\title{
Critical Learning: Critical Discourse Analysis in EFL Teaching
}

\author{
Dolores Fernández Martínez \\ University of Las Palmas de Gran Canaria, Las Palmas de Gran Canaria, Spain \\ Email: dfernandez@dfm.ulpgc.es
}

\begin{abstract}
Discourse analysis, the study of language use within its social context, has plenty of utilitarian aspects, especially for language learners. Besides being a means of communication, language is a practice that not only constructs, but is also constructed by the ways language learners understand themselves and their social environment. Critical discourse analysis promotes the application of critical thinking to social situations and the unveiling of hidden connections between language use, ideology and power. This paper aims to demonstrate how critical discourse analysis can be implemented in foreign language teaching in order to help students develop their internal values and critical thinking skills. The main principles of critical discourse analysis can be incorporated in order to turn a song, a t-shirt slogan or an email into the subject of linguistic exploitation and socio-cultural debate.
\end{abstract}

Index Terms - discourse analysis, critical discourse analysis, language teaching, language learning

\section{From DisCOURSE ANALYSIS TO CRITICAL LEARNING}

Discourse analysis is a broad and fast-developing interdisciplinary field concerned with the study of language use in context. In 1952 Harris published a paper with the title "Discourse Analysis", where he claimed for solutions to the problems of both the continuation of linguistic description above the sentence and the correlation between linguistic and non-linguistic behaviour. In the following decades some outstanding works (Brown \& Yule, 1983; Sinclair \& Coulthard, 1975; Stubbs, 1983; Van Dijk 1985a, 1985b) were published, constituting a solid background for a wide range of succeeding research appearing within the framework of discourse analysis. Those works agreed on presenting discourse analysis as a field interested in investigating the use of the language at a supra-sentential level and within its social context.

Discourse analysis includes somewhat diverse theoretical and methodological approaches from linguistics, anthropology, philosophy, psychology and sociology. Far from being a coherent paradigm of clear-cut practices, there is still an on-going proliferation of theoretical perspectives, methodological devices and research topics which in the last years have unveiled, among many others, the potential of discourse analysis as an instrument for teaching languages. In 1991, McCarthy wrote Discourse Analysis for Language Teachers as a practical introduction to discourse analysis for language teachers. McCarthy evaluated different teaching approaches and outlined new ways of looking at grammar and vocabulary based on the insights of discourse analysis. Although in the Preface McCarthy opposed to the idea of considering discourse analysis as a method of teaching languages, three years later (McCarthy \& Carter, 1994) he clarified his position by supporting the idea of providing learners with a meta-language to analyse language. Leaving aside the terminological debate about the assignment or not of the label method to discourse analysis, McCarthy and other works in the same vein (Norton, 2008) have contributed to acknowledging the importance of discourse analysis for some language teaching approaches.

Cots' (2006) proposal to teach "with an attitude" exemplifies in a very practical way how critical discourse analysis (CDA) can be implemented in foreign language teaching in order to activate the learners' capacity to evaluate linguistic and social reality in a critical way. CDA defends the study of discourse as a tool for the social construction of reality, but also as an instrument of power and ideological control that "implies a dialectical relationship between a particular discursive event and the situation(s), institution(s) and social structure(s) which frame it" (Fairclough \& Wodak, 1997: 258). Van Dijk (2001: 96) defined CDA as "discourse analysis "with an attitude". The term critical distinguishes itself from the merely descriptive purposes of other analysts, such as Sinclair \& Coulthard (1975) or Stubbs (1983), "whose method suffers from an inherent weakness of explanatory power" (Teo, 2000: 12). Fairclough (2001b: 4) talked of a critical purpose which aimed to examine the hidden connections between language, power and ideology. Non-critical or descriptive approaches underestimate the way in which discursive practices are socially moulded or their social effects (Fairclough, 1995: 23).

Discourse analysis can be characterized as an instrument to approach problems, to question socio-linguistic reality and, if possible, to change it. Through discourse analysis, students learn to sharpen their critical thinking and to tackle the cultural component, which meets the recent demands for treating culture as a new language skill (Norton, 2008; Tomalin, 2008). Advocates of critical teaching perspectives (Thornbury, 2009) have focused on the relationship between language learning and social change, and have appealed for more social teaching and contextually sensitive 
methods. Rather than being considered as a means of communication, language maintains a bidirectional relationship with learners and their social environment: "rather, it is a practice that constructs, and is constructed by, the ways language learners understand themselves, their social surroundings, their histories, and their possibilities for the future" (Norton \& Toohey, 2004: 1). The classroom is the initiating platform to make students aware of their capacity both to value the information they receive and to bring about social change out of the classroom. As an answer to the question of the methodology which best suits to the teaching of culture in the English language classroom, discourse analysis has provided valuable insights into the concepts of language analysis leading to culture awareness. The call for critical approaches or attitudes when assessing culture has produced a type of social teaching which will lead students to become critical citizens.

\section{CRITICAL LEARNING: A PROPOSAL}

This paper aims to exemplify how CDA can be implemented in foreign language teaching in order to help students develop their internal values and critical thinking abilities. The proposal presented here is divided into three main sections: the first one gives a balanced insight into basic theoretical concepts within discourse analysis; the second section offers a set of tools for analysing texts, mainly centred on cohesive devices; and the third one, which constitutes the focus of attention of this paper, illustrates how students perform critical language learning through the analysis of a wide variety of authentic texts. The following chart summarizes the topics included in each section labelled, respectively, "Theory notes", "Tools for discourse analysis" and "Analysing texts":

TABLE 1 .

SUMMARY OF SECTIONS AND TOPICS

\begin{tabular}{|l|l|l|}
\hline \multicolumn{1}{|c|}{$\begin{array}{c}\text { Part I: } \\
\text { Theory notes }\end{array}$} & \multicolumn{1}{c|}{$\begin{array}{c}\text { Part II: } \\
\text { Part III: } \\
\text { Analysing texts }\end{array}$} \\
\hline 1. Discourse analysis: Introduction & 1. Parts of speech & 1. "Yes, we can" \\
\hline 2. Social dimension of discourse & 2. Content and function words & 2. The zodiac \\
\hline 3. Ideology and power in discourse & 3. Cohesion and coherence & 3. Song: Amy Winehouse's "Rehab" \\
\hline 4. Text structure & $\begin{array}{c}\text { 4. Cohesive devices } \\
\bullet\end{array}$ & 4. T-shirt slogans \\
5. Methodological cohesion & 5. Interview with Angelina Jolie \\
\cline { 3 - 4 } & • Grammatical cohesion & 6. Hoax e-mail \\
\hline
\end{tabular}

The analytical suggestion presented in Part III assumes the necessity of a preceding theoretical and methodological framework. As stated by Schiffrin (1997: 75), "Although the study of discourse is often termed discourse analysis, the use of this term should not imply a field that is void of theory". The success of any analytical undertaking is subjected to the formulation of some compatible theoretical presuppositions on which the analysis will be based. Or rather seen from another perspective, the failure in the examination of theoretical presuppositions can lead to a mistaken analysis (Jones \& Viechnicki, 1997). In order to perform a critical analysis of the text, students should count both on some kind of instruments to work with and some specific theoretical knowledge about the premises of CDA which will guide them in the stage of analysis.

In part I (Theory notes), students are introduced to the origins and basic parameters of study of discourse analysis, and to the concept of discourse as contextually activated text (Widdowson, 1995: 164). Within the relationship of bidirectionality maintained between discourse and social context, CDA incorporates ideology and power as inherent variables to the social dimension of the text (Fairclough, 1995). The theoretical part pays special attention to the tenets of CDA which students will have to apply in Part III, specifically:

- CDA proposes to study discourse within a social and ideological context marked by relations of power and inequality.

- CDA values the text not only as a tool for the social construction of reality, but also as an instrument of control.

- CDA aims to uncover implicit meanings and strategic purpose. "What is 'in' a text may be explicit or implicit [...] The implicit content of a text is a halfway house between presence and absence" (Fairclough, 1995: 5).

Sections 4 and 5 are to be taken as an introduction to the methodological counterpart of theory. They concentrate mainly on the assumption of different levels of analysis, above and below sentence level, and on the relationship of interdependence which links discourse analysis and systemic functional grammar. Some of the most outstanding discourse analysts (Fairclough, 1995, 2001a) have favoured systemic linguistics, especially Halliday's (2004) Introduction to Functional Grammar, as the most suitable analytic tool for their explorations. In this sense, Part II (Tools for discourse analysis) concentrates on cohesive devices as depicted primarily by Halliday's grammar.

Parts I and II have taken into account that the methods used for discourse analysis emerge from implicit theoretical presuppositions about the nature of language and the complex relationship between language, communication and socio-cultural life (Schiffrin, 1997). The intertwining of theory, method and practice in discourse analysis is a principle which cannot be overlooked. However, despite the provision of instruments for analysis, the link between the three elements rests on the assumption of the use of common sense. Students must assume that the perception of each text is essentially subjective, since their content appeals to them differently. Given that discourse analysis is basically interpretative reading, there are no rigid guidelines to follow. Students are encouraged to make use of logical thinking and to be aware of the fact that the best method of analysis is the application of common sense. 
With the background provided by the previous theoretical and methodological outline, students are subsequently introduced to some authentic texts. Throughout their analysis, some guiding questions will be supplied in order to help them perform a critical analysis of the text in the terms studied in Part I and II. Students will work individually or in groups to think of a variety of interpretations. They will evaluate how the tools provided help them to analyse real texts for practical purposes. They will try to reveal the hidden motivations or meanings behind the text, identify strategic linguistic structures and discern how the text imbibes social or cultural aspects. They should be able to identify any value-laden language and perceive how the authors predispose the readers or determine their viewpoint.

The texts selected for analysis represent different domains of the students' everyday life, mainly attached to nonformal or entertaining contexts. Authentic materials are more likely to connect with their interests and prompt their motivation and satisfaction. Students should learn language through exposure to different types of texts and be aware of the fact that the study of discourse can be applied to any text, problem or situation. All texts are accessible to analysis by the existing methods of linguistics. Proving that, the main principles of CDA will be incorporated in order to turn a song, a t-shirt slogan, an interview or an email into the subject of linguistic exploitation and socio-cultural debate. The following activities, included in Part III, represent different examples of the types of texts students may analyse applying the theory and methods previously studied.

\section{A. "Yes, We Can"}

By way of introduction to this practical part, students' attention is focused on the strategic purpose of a very wellknown expression and on the reactions it may produce on them. Discourse analysis involves looking at both language form and function. For that reason, they are asked to value the form of the structure "Yes, we can" and then attach a purpose or goal to it, especially considering the context in which it was created, namely, Obama's presidential election campaign. Supplementary contextual information will help them be aware of how Obama offered a new kind of politics with a skilful oratory and a high potential for reconciliation and change. With this initial activity students get into the world of politics and Obama, as a political and media celebrity, in an attractive and gentle manner, restricting to a miniature size what other scholars have done with Obama and political discourse, within CDA, on a larger scale (Horváth, 2009).

These are the types of questions used to guide students in their analysis:

- Do you know what a political slogan is?

- What is your reaction when you hear or read this expression? Can you perceive any goal or aim in it?

- What information does each word convey? Do you think the three words which make up this slogan have been strategically chosen?

- Do they have any meaning outside the context in which this slogan appeared? Try to find some contextual information on the Internet.

In the next activity, students use the information they have previously obtained in order to create their own slogan to represent them as candidates for vice-chancellor of their university. In the last part of the task they are faced with the distinction between interpretation and intention. Schiffrin (1997: 79) established a duality interpretation/intention assuming that both processes are different because the contexts of interlocutors are also different. Others, such as Harris (1952), Van Dijk (1985b) or Widdowson (1995) rejected excluding both elements since they considered that intentions give sense to the interpretation of the text. In any case, students are encouraged to tackle discourse analysis as an interpretative enterprise in which processes of production and reception should be as close as possible. When creating their slogan, they should connect as much as possible with the expectations of the receivers. When interpreting the slogans of their classmates, their interpretation should connect with the intentions of the authors as much as possible. Here are some examples of guiding questions to be used:

- In what way do you think your slogan will impact most on people? Are you going to follow any strategy?

- How many words are you going to choose? Do you think the effectiveness of your slogan depends on its length? On the word classes used (nouns, verbs, adverbs, pronouns, etc.)?

- Comment on the slogans created in class, choose the best slogan and justify your election. Is there a coincidence between the intention of the authors and the interpretation of the class?

In order to reinforce the significance of contextual connections, students will have to guess if other political slogans are real or not. The use of words with negative connotations (probably inconceivable nowadays) or the fact that some of the slogans may sound like advertisements or TV programmes today support the idea of the effectiveness of the messages within their own context. Here are some examples:

- A chicken in every pot. A car in every garage

- Are you better off than you were four years ago?

- I like Ike

- I still like Ike

- It's the economy, stupid

- Ma, ma where's my pa?

- Morning again in America

- Better dead than red 


\section{B. The Zodiac}

Small et al. (2008) have used CDA to study advertisements in in-flight magazines as powerful instruments representing the norms and values to which travellers should supposedly adhere. Texts from activities B and E have been taken from Iberia's magazine Ronda (2009: 29, 38-39). Our purpose has been to emphasize the idea that the potential for analysis of this type of publication goes beyond that of advertisements and extends to all its contents. Any type of text included in the magazine, however innocuous it may seem, can be the subject of exploration within a CDA framework. For CDA, the text is an instrument of control which tries to predispose the addressee. In this case, the texts of the zodiac operate as injections of high self-esteem on the reader. By comparing both signs of the zodiac it can be noticed that they also contain equally value-laden language and that the similarity of structures makes us feel suspicious about the absence of any strategically fixed design.

Aries

Congratulations! The Sun, luminous king of stars (conscious power), reinforces the brilliant, energetic and enterprising side that makes you the centre of attention. Venus, goddess of love and a guardian angel of striking beauty, enfolds and protects you, bringing you hours of pleasure and inviting you to be more strategic, patient and affable. Lavished attentions, prestige, privilege and smiles.

Taurus

If born before 1 May, this is a time of enormous charisma, maximum power and tremendous guts. Appeal to your self-control! If born between 2 and 13 May, you are at the centre of things, distinguished but groaning under the heavy burden of responsibility. Born afterwards? Watch out for deceit, manipulation, blackmail, harassment and pressure. Indulge yourself, but without falling into self-neglect or depression.

- How do these texts make you feel?

- Which similarities can you notice between them?

- Can you extract any explicit or implicit connotations of power from them?

\section{Song: Amy Winehouse's "Rehab”}

The application of discourse analysis to the study of music is not something new, as exemplified by Carlisle's (2007) research study into competing discourses in digital music. CDA examines discourse structures within social contexts marked by inequality between social members and by the relations of power and authority enacted between them. Through the lyrics of this song, students can verify how connotations of authority and control can go beyond political, religious, educational or journalistic contexts. The singer uses the song to undermine in a rather provoking manner the authority of parents, teachers and doctors (especially manifest in the repetition of the negation "no, no, no") and to transfer it to musicians "Ray" and "Mr. Hathaway". Here is a fragment from the lyrics and some sample questions:

They tried to make me go to rehab

I said no, no, no.

Yes I've been black, but when I come back

You won't know, know, know.

I ain't got the time

And if my daddy thinks I'm fine

He's tried to make me go to rehab

I won't go, go, go.

I'd rather be at home with Ray

I ain't got 70 days

Cos there's nothing, nothing you can teach me

That I can't learn from Mr. Hathaway

Didn't get a lot in class

But I know it don't come in a shot glass

- Can you analyse the relationship the singer maintains with other people from a critical discourse analysis point of view?

- Whose authority does she confront? Who does she confer authority to?

\section{T-shirt Slogans}

In this activity students face a quite engaging task, namely, a CDA of the short messages they may encounter everyday on t-shirts. They will have to examine both how slogans may confer power to the people wearing the t-shirt and how they can control or manipulate the reader in some way. Superiority in the examples provided is determined by economic or family position, nationality or strength. Students will have to employ the insights obtained in order to create their own t-shirt slogan. Here are some examples of $\mathrm{t}$-shirt slogans and some guiding questions:

- I'm single if you are rich

- Catch me if you can 'cos I'm the England man

- World's bestest mum

- I am Spartacus 
- Can you observe any connotations of control or inequality?

- How are the people wearing the t-shirt and those who read the slogan portrayed?

- Write your own slogan for a t-shirt. Then comment on the slogans created in the class, choose the best one and evaluate if there is a coincidence between the intentions of the authors and the interpretation of the class.

\section{E. Interview with Angelina Jolie}

Journalistic discourse has been one of the fields of study which has attracted more attention from discourse analysts (Teo, 2000). Before analysing a real interview with Angelina Jolie, students are invited to play the role of a journalist who has to prepare an interview with this world-wide famous film star. Students should be conscious of the value of words in order to control the interviewee and direct the conversation in such a way that it meets the demands of a reader mainly interested in her private life.

- How would you start the conversation? Is it strategic to do it by focusing on her private life?

- How can you keep a balance between the interest of the readers in her private life and the likely reluctance of Angelina to talk about personal matters?

- By analysing cohesive devices, try to establish the strategy used by the journalist in the following interview to switch from Angelina's public career to her private life:

- Your career has alternated between action and emotion. Is that coincidental or intentional?

- With six children, it must be practically impossible to be everywhere you're asked to be. How do you manage to combine your family, your work and your philanthropic activities?

- Are you working again soon?

- Do you and your partner have time to be alone?

- How do they [your children] react to the photographers who are always following you around?

- Are your elder children aware their parents are famous film stars?

- Are you thinking of having any more children?

- You've played mothers in your last four films, albeit metaphorically in the case of Wanted. Does your maternal instinct have an influence on your choice of parts?

- On the other hand, your role in the last film, The Changeling, seems to have helped your own family to grow...

- Your character becomes the object of unfounded criticism and accusations. As a public figure who appears on magazine covers around the world, do you identify with her in that respect?

- Would you oppose the authorities and the political system as she does?

\section{F. Hoax E-mail}

Electronic mail has become a regular part of our Internet experience both for personal and business-related communications. It is a tool of mass global communication with the advantages of simplicity, cheapness and flexibility. However, this fact has also led to an increase of deceptive online messages in the last few years which have turned into objects of study (Chiluwa, 2009). The analysis of hoax e-mails evinces how being excessively explicit may affect the communicative effectiveness of the text. Implicit contents are placed in the limit between what has to be said and what may be assumed. When strategies are not used in a subtle and measured way, the persuasive nature of the text is blocked. Thus, strategies turn into xtrategies with a highly dissuasive effect on the reader.

On this occasion students should look for a hoax e-mail in their inbox and analyse it answering these types of questions:

- Analyse how the receiver and sender are portrayed in the message.

- Which strategies are used to make the information more convincing and attract the attention of the addressee?

- Which structures urge the receiver to act in some way?

- Do you consider the e-mail as strategic or xtrategic? Why?

\section{CONCLUSION}

CDA promotes the application of critical thought to social situations and the unveiling of strategies in texts. Discourse analysis, and more specifically, critical approaches offer the learner new skills to interpret society and culture. Teachers can improve their teaching practices by investigating actual language use both in and out of the classroom. Likewise, discourse analysis stimulates students to reflect on the huge amount of analysable information they receive every day through different means. The proposal offered in the paper combines theory, method and practice, and has been exemplified through its application on apparently innocuous or entertaining texts, quite different from traditionally considered socially relevant discourse. Connotations of power, control or social inequality can also be present in the zodiac or in the lyrics of a song. Discourse analysis is not restricted to significant texts and contexts. Journalists, writers of e-mails, composers of songs and creators of slogans are conscious of the potential of words to have an impact on the reader and shape his feelings and behaviour. This proposal also persuades students to employ the insights obtained from their analysis in order to produce their own brief and effective messages. Every kind of text offers the learner a new platform to apply his critical skills and reveal hidden meanings or motivations. Critical learning awakens students' 
curiosity about their surrounding information and leads them to think that they can be manipulated while they think they are just being informed. All in all, the classroom presents tangible and attractive ways of interpreting contemporary culture; it is an excellent forum for teaching discourse analysis and for making students aware that there is a rich and complex world outside to be analysed and criticalized.

\section{REFERENCES}

[1] Brown, G. \& Y. George. (1983). Discourse analysis. Cambridge: Cambridge University Press.

[2] Carlisle, J. (2007). Digital music and generation Y: Discourse analysis of the online music information behaviour talk of five young Australians. Information Research 12.4. http://InformationR.net/ir/12-4/colis/colis25.html (accessed 1/10/2011).

[3] Chiluwa, I. (2009). The discourse of digital deceptions and “419" emails. Discourse Studies 11, 635-660.

[4] Cots, J. M. (2006). Teaching "with an Attitude": Critical discourse analysis in EFL teaching. ELT Journal 60.4, 336-345.

[5] Fairclough, N. (1995). Critical discourse analysis: The critical study of language. London: Longman.

[6] Fairclough, N. (2001a). Critical discourse analysis as a method in social scientific research. In Wodak \& Meyer (eds.), 121-138.

[7] Fairclough, N. (2001b). Language and power (2nd edn.). London: Longman.

[8] Fairclough, N. \& R. Wodak (1997). Critical discourse analysis. In T. A. Van Dijk (ed.), Discourse as social interactions. London: Sage, 258-284.

[9] Halliday, M. A. K. (2004). Introduction to functional grammar (3rd edn.). London: Edward Arnold.

[10] Harris, Z. S. (1952). Discourse analysis. Language 28.1, 1-30.

[11] Horváth, J. (2009). Critical discourse analysis of Obama's political discourse. In M. Ferenčík \& J. Horváth (eds.), Language, literature and culture in a changing transatlantic world, International conference proceedings. Presov: University of Presov, 45-56.

[12] Jones, E. \& G. B. Viechnicki. (1997). Special issue on the importance of theory in discourse analysis. Language \& Communication 17.2, 71-74.

[13] McCarthy, M. (1991). Discourse analysis for language teachers. Cambridge: Cambridge University Press.

[14] McCarthy, M. \& R. Carter. (1994). Language as discourse: Perspectives for language teaching. Essex: Longman Group.

[15] Norton, B. \& K. Toohey (eds.) (2004). Critical pedagogies and language learning. Cambridge: Cambridge University Press.

[16] Norton, S. (2008). Discourse analysis as an approach to intercultural competence in the advanced EFL classroom. http://arrow.dit.ie/cgi/viewcontent.cgi?article=1000\&context=aaschlanart (accessed 14/11/2010).

[17] Ronda. Iberia Magazine (April 2009). Madrid: Iberia.

[18] Schiffrin, D. (1997). Theory and method in discourse analysis: What context for what unit? Language \& Communication 17.2, 75-92.

[19] Sinclair, J. M. \& M. Coulthard. (1975). Towards an analysis of discourse: The English used by teachers and pupils. London: Oxford University Press.

[20] Small, J., C. Harris \& E. Wilson. (2008). A critical discourse analysis of in-flight magazine advertisements: The "social sorting" of airline travellers? Journal of Tourism and Cultural Change 6.1, 17-38.

[21] Stubbs, M. (1983). Discourse analysis: The sociolinguistic analysis of natural language. Oxford: Blackwell.

[22] Teo, P. (2000). Racism in the news: A critical discourse analysis of news reporting in two Australian newspapers. Discourse and Society 11.1, 7-49.

[23] Thornbury, S. (2009). Dogme: Nothing if not critical. http://www.teachingenglish.org.uk/think/articles/dogme-nothing-if-notcritical (accessed 14/11/2010).

[24] Tomalin, B. (2008). Making culture happen in the English language classroom. http://www.teachingenglish.org.uk/think/articles/making-culture-happen-english-language-classroom (accessed 14/11/2010).

[25] Van Dijk, T. A. (2001). Multidisciplinary CDA: A plea for diversity. In Wodak \& Meyer (eds.), 95-120.

[26] Van Dijk, T. A. (ed.) (1985a). Handbook of discourse analysis: Disciplines of discourse (vol. 1). London: Academic Press.

[27] Van Dijk, T. A. (ed.) (1985b). Handbook of discourse analysis: Dimensions of discourse (vol. 2). London: Academic Press.

[28] Widdowson, H. G. (1995). Discourse analysis: A critical view. Language \& Literature 4.3, 157-172.

[29] Wodak, R. \& M. Meyer (eds.) (2001). Methods of critical discourse analysis. London: Sage.

Dolores Fernández Martínez is a lecturer in the Department of Modern Languages and Literature, University of Las Palmas de Gran Canaria. She currently teaches discourse analysis and English as a Foreign Language. Her research interests include discourse analysis, critical discourse analysis, systemic linguistics and Old English. 